Letter

\title{
Neurocysticercosis - Islam and Other Religions
}

\author{
Beuy Joob, ${ }^{1, *}$ and Viroj Wiwanitkit ${ }^{2}$ \\ ${ }^{1}$ Medical Academic Center, Bangkok, Thailand \\ ${ }^{2}$ Hainan Medical University, China \\ "Corresponding author: Beuy Joob, Medical Academic Center, Thailand. Tel: +66-24658292, E-mail: beuyjoob@hotmail.com
}

Received 2016 November 08; Revised 2016 November 21; Accepted 2016 November 26.

\section{Dear Editor,}

The recent article on Mirsane et al. (1) is very interesting. As noted by Mirsane et al. (1), neruocysticercosis should not exist in the Islamic community and the Islamic principle is the best way for prevention of neuroysticercosis. In fact, many other religious practices are also useful for prevention of neurocysticercosis. It is stated that vegetarianism in Hinduism and Chinese Buddhism might also be useful in preventing neurocysticercosis. However, what's interesting is the existed cases of neurocysticercosis in several communities with religious practices that support no neurocysticercosis. In a recent report, "diet (vegetarian vs. non-vegetarian and consumption of raw veg- etables)" has no "any association with seropositivity (2)." Therefore, neurocysticercsosis should still be a differential diagnosis of a space-occupying lesion in any community regardless the religious background.

\section{References}

1. Mirsane SA, Mirsane SM, Oraei N. Islam and Neurocysticercosis. Arch Neurosci. 2016;3(4):38060. doi: 10.5812/archneurosci.38060.

2. Cherian A, Syam UK, Sreevidya D, Jayaraman T, Oommen A, Rajshekhar $\mathrm{V}$, et al. Low seroprevalence of systemic cysticercosis among patients with epilepsy in Kerala-South India.J Infect Public Health. 2014;7(4):2716. doi: 10.1016/j.jiph.2013.08.005. [PubMed: 24684839]. 